\title{
Scratching the Knowledge Base Surface of Ministry of Education (MOE) English Teacher Supervisors in Iran
}

\author{
Seyed Ayatollah Razmjoo \\ Department of Foreign Languages \& Linguistics, Shiraz University \\ Shiraz, 71964-85115, Iran \\ Tel: 98-711-613-4517 Email: arazmjoo@rose.shirazu.ac.ir \\ Alireza Rasti (Corresponding author) \\ Department of Foreign Languages \& Linguistics, Shiraz University \\ Shiraz, 71964-85115, Iran \\ Tel: 98-711-613-4517 Email:alirezarasti77@gmail.com
}

Received: 31-10-2013

doi:10.7575/aiac.ijalel.v.3n.2p.39
Accepted: 01-12-2013

Published: 01-03-2014

\begin{abstract}
Based on the expert observation that the teacher "supervisor's role is, in part, culturally defined" (Bailey, 2006, p.6), and the perceived gap that few supervisors receive formal training, in the current study, the researchers report on the views of Ministry of Education (MOE) teachers and supervisors in the Iranian context as to what constitutes the knowledge base of supervisors. Having conducted qualitative content analysis on the data gleaned from interviews with the teachers and supervisors and open-ended questionnaires, we came up with a framework of supervisory skill/knowledge domains - one encompassing public relations skills, subject matter knowledge, pedagogical content knowledge, and contextual sensitivity. The results show that teachers by and large, by voicing their discontent with current supervisory routines, opt for humanistic supervisory procedures. The study, hoping to be taken up with more supervisory knowledge base studies, ends with advice on building supervisory preparation courses into existing teacher development programs.
\end{abstract}

Keywords: Iran, language teacher supervision, knowledge base, Ministry of Education, pedagogical content knowledge

\section{Introduction}

The concept of teacher supervision in general and language teacher supervision in particular, straightforward as it may appear at first sight, is a messy and complex one (Stones, 1984). Part of the confusion surrounding the concept, as found in the relevant literature, arises from the fact that there is no dearth of (near)synonymous terms referring to the undertaking of actively going about observing and evaluating the way a teacher teaches a given content area (in this particular regard, a second or foreign language) (Anderson, 1982). In addition, it is not atypical of authorities in the field to lament the fact that the so-called language teacher supervisors do not receive any (proper) formal training. In fact, in the majority of cases, as it is the norm, it is assumed that the supervisorial skills are a corollary to and a byproduct of good teaching. The simplistic line of argument reads if someone is a competent teacher then it follows that they can make good supervisors as well'. It is, however, far from true. This complaint is given full vent to by Bailey (2006) when (in line with relevant others such as Daresh, 2001, and Stones, 1984) she says

Unfortunately, very few language teachers ever receive any formal preparation for carrying out supervisors' responsibilities. It is often assumed that teachers who are promoted to supervisorial positions will automatically know how to supervise because they have seniority or because they have displayed leadership qualities. Some are appointed as supervisors because they are stable, cooperative employees. Still others attain teacher supervision positions because they are recognized as effective teachers. If they continue to teach in their supervisory positions, presumably they will serve as good role models ... (p. 3).

As is evident from the above quote, the most pragmatic criteria for recruiting language teacher supervisors vary across contexts, and occasionally, over time. It follows then that, in the eyes of the experts in the field of language teaching, the status quo needs a change - a sort of reform informed, inter alia, by sound theoretical considerations. This theory base, as far as language teacher supervision is concerned, is, in the words of Alfonso, Firth, and Neville, quite "thin" (as cited in Bailey, 2006, p. 3).

One facet of the 'thinness' of the theory base of teacher supervision relates to the fact that supervisorial skills and knowledge types need to be delineated as clearly as possible. This gains importance because in the views of some experts the act of supervising (language) teachers is socially, culturally, and politically situated. "The supervisor's role is, in part, culturally defined and conceptually located in the educational and political history of a particular region" 
(Bailey, 2006, p.6). One may venture into saying that the other 'part' has to do with the skills demanded of supervisors based on a probe into the common denominators of the issue as addressed by the relevant research. The present study, however, is a localized attempt at tapping into the views of the Iranian (secondary education) language teachers and supervisors to identify the knowledge base of language observers working within the Iranian context.

Another point worth mentioning is that in the face of theoretical and practical challenges to the issue of teacher supervision, and even pressures exerted from outside e.g., the need for teachers' work's quality check and accountability to the stakeholders involved in that matter, the undertaking of language teacher supervision is gaining momentum. Given this context, the newly born discipline (if one may venture to call it so) and profession (with required professional standards thereof) is beginning to come into being slowly but surely. This is the result of the upsurge of interest in the issue we have observed in the late twentieth-century and the turn of the new one.

\section{1 Objectives of the Study}

Having worked as a Ministry of Education (henceforth, MOE) directing teacher (i.e., supervisor) in the Iranian context assigned to the duty of supervising language teachers and having reviewed the relevant literature, the authors have come across many negative labels attributed to the supervisors and their tasks by (language) teachers. Initially, there is a mutual mistrust of, we would say, the other party's job. This observation/supervision phobia is a sentiment which, according to Acheson and Gall, (2011, p.82) 'still stings', even in an age hastening presumably towards more humanistic approaches to supervision. This adds to the thorniness of the issue. Further, to add fuel to the flames of current supervisory practices and procedures, it is a task requiring, inter alia, a high degree of interaction and, at times, cooperation, between the various players needing tactfulness, especially, on the part of the supervisor. Also, as it was mentioned earlier, there is a cultural side to the issue of (language) teacher supervision which adds to the complexity of it. For these reasons, it behooves well to say that any conceptualization of MOE language teacher supervision must take into account a well-established compromise between the main participants involved in the job i.e., MOE teachers and supervisors, at the very least, for that matter. Unless such a compromise is seen to by any researcher, the provision of a localized framework for describing the various duties of a supervisor is of no use in a practical sense.

In light of the said compromise, the present study sets out to provide a (re)conceptualization of the MOE supervisorial skills/knowledge types as seen through the viewpoints of supervisors and language teachers alike in the Iranian context. The small-scale study is motivated partly by our emic work experiences as directing teachers involved in supervisory roles and by the yawning gap in the literature in regard to the issue of MOE language teacher supervision in the Iranian context.

It is analogically maintained that presently in the "post-Fordist" era which is concerned, among other things, with and about "quality debate" (Tuffs, 1995), language teaching is a business informed by "mass consumption" (ibid.). Thus it makes sense to say that the enterprise should cater more to the needs and expectations of the learners. In the words of Bailey (2006)

During the later decades of the past century, teacher supervision emerged as a career track in language education. Perhaps this trend developed because language teaching has become a commercial enterprise (italics added), and supervisors are needed to make sure that customers get what they pay for (p.3).

In light of such observations, it may not be something of an exaggeration to hold that supervision is a matter of life-ordeath to the business of language education. In order for such an education to, initially, survive and, later, hopefully thrive, it should make arrangements for the recruitment and/or training of supervisors who possess certain knowledge types and/or skill domains. It goes without saying that the success of any supervisorial undertaking hinges to a great extent on defining the knowledge base of supervisors (in this particular regard, MOE observers) and moving on to the professional development of them.

Against this backdrop, this research strives to address the following broad research question:

How do Iranian MOE supervisors and English teachers teaching at public schools conceive of the necessary supervisorial skills and/or knowledge types?

\section{2 Significance of the Study}

The present study has its roots, among other things, in the present researchers' experiences as MOE English teacher supervisors. Part of the duties assigned to such teachers in the Iranian context, in addition to teaching, can roughly be associated with teacher supervision for developmental and evaluative purposes. The supervisors, however, are (to borrow a term from Goldsberry, 1988) 'nominally' supervisors in the sense that they have been delegated the right to language classroom observation but, for the most part, they fail to see to their duties or achieve desirable results for a host of reasons, including the teachers' apparent dislike and mistrust of them, lack of supervisors' cognizance of and familiarity with the genres (e.g., checklists, field notes, ...) and practices (e.g., holding post-observation conference sessions, establishing rapport with the practitioners, ...) of the profession of teacher education. Against this background, we are bound to come across a huge research gulf in the said domain. The study also hopes to galvanize the population of, especially domestic, investigators into 'opening up' on the issue. The rekindling of interest in the matter by 
theoreticians and practitioners alike will be liable to have far-reaching positive consequences for the educational system of the country at the secondary level.

\section{Literature Review}

\section{1 Review of Models of Teacher Supervision}

The literature pertaining to the fledgling field of teacher supervision reveals (or, rather, assumes) a trend from evaluative supervisory duties towards developmental growth of practicing teachers and teachers in training (Bailey, 2006; Gebhard, 1984; Kennedy, 1993). This mostly historically progressive pattern is evident in diversified taxonomies of and approaches to supervisory procedures.

One of the first models of teacher supervision is the one set forth by Goldsberry (1988). The model distinguishes between three types of supervision: nominal supervision, whose purpose is to maintain the status quo; prescriptive supervision, which, as the negative label thereof indicates, seeks to rectify the deficiencies evident in a teacher's work; and, reflective supervision, whose purpose is to help teachers refine and sharpen their own teaching strategies and practices. In sum, Goldsberry's framework shows a trend from downright passivity on the part of the supervisor to adopting an authoritarian stance to the job of teaching to the provision of some sort of supportive scaffolding to the teacher.

Perhaps the most well-known model of all is the one proposed by Acheson and Gall (1997). The model assumes six types of supervisory roles deployed and employed by the supervisors in general education: counselor, coach, consultant, inspector, mentor, and cooperating teacher. Acheson and Gall's model captures the nuances of the job more exhaustively than do the previous generalist models.

As far as language education domain is concerned, Freeman (1982), as a known figure in the field, distinguished between the supervisory, nondirective, and the alternative options for teacher supervision. The first option is equivalent to the prescriptive supervisorial role as explicated on by Goldsberry. The second option available to some supervisors is nonjudgmental. And the supervisors in the last role are expected to provide the teachers with some alternatives so that they can choose from among them for a change in or betterment of their classroom practices.

Finally, Genhard (1984), highly inspired by the work of Freeman, extended his model to include two more roles for supervisors and thus provided one of the most exhaustive frameworks in the field of language education. The additions included were collaborative and creative supervisory functions. The former is one informed by a shared problemsolving by the supervisor and the teacher alike, whereas in the latter one, the supervisor is expected to "switch roles" (Bailey, 2006, p. 15) and be selective about the kinds of supervisory strategies they use while conducting the task of supervision.

In summary, a review of the different models of teacher supervision, as mentioned before, is quite telling in the sense that we witness a trend towards a compromissory agreement between the main parties involved in the teaching/learning process i.e., the teacher and the supervisor. Here (in a similar vein as the one vocalized by such figures as Kennedy, 1993) we can envisage a cline with two poles one of which describing a 'prescriptive' traditional supervisory model and the other leaning more towards a (collaborative) clinical one informed by "stressed equality between the participants" (p. 162). It appears that supervisors in some parts of the world are saying goodbye to a paternalistic style of getting things done and are adopting more learner-centered approaches to student/practicing teachers. This shift is bound to have some significant implications for language teacher education and supervision.

\section{2 Language Teacher Supervision in the Iranian Context}

In Iran, as far as private language institutes are concerned, the act of supervising language classrooms is much in practice. For instance, in the mostly state-backed Iran Language Institute (the ILI), the most prestigious language institute nationwide, attempts are made on the part of the supervisors to regularly observe the way teachers set out to use their pedagogical skills. Therefore, the discourse community there is much familiar with the routines and traditions of language classroom observation and members take the job seriously.

In the Iranian educational system, however, a large lacuna exists in the sense that the act of supervision, even if it is done at all, is done on a quite ad hoc basis. In such a system, there are some guiding teachers (and their primary job is to teach!) who are supposed to pay weekly visits to language classrooms and, apart from evaluating teachers' practice, help them develop and grow pedagogically. They are, however, as already mentioned, 'nominal' supervisors who try to maintain a 'façade' of supervision. Part of the problem stems from the fact that they are not, as mentioned before, professionally equipped to take over their supervisorial duties. In our emic experience, they are called upon from time to time to give lectures and workshops and to try to keep teachers up-to-date with the most recent research findings and practical advice of the experts in the field but no attempt whatsoever is made at providing them with their necessary skills (professional skills, 'people' skills, etc.) by the top managers in the educational system of the country. The assumption is again a familiar one. If they are able to teach well (and further if their views dovetails well with those of authorities), they will be naturally adept at carrying out their observational/supervisorial acts!

In Iran currently (2013) there seems to be some big changes in progress with the middle education being subsumed into the secondary education. Students study English as a subject at school for 6 years. One of the most important aims of the educational system, as promulgated by the Ministry of Education, is the mastery of at least one foreign language. But, criticism of the quality of language teaching in the system by the experts, for the most part, is much in the air (Dahmarde, 2006, 2009; Kiany, Mahdavi, \& Ghafar Samar, 2011; and Pishghadam \& Mirzaee, 2008). 
In Iran, to our best knowledge, quite rarely have studies on the field and profession of language teacher supervision in general and, specifically, on MOE language teacher supervision in an Iranian context been done by researchers to date, let alone any work done on the knowledge base of supervisors. One such study worth mentioning, methodically deficient as it is (since it does not render, as claimed in the title, any model for teacher observation), is the one conducted by Akbari, Ghafar Samar, \& Tajik (2006). The study, at the most, gives one some 'principles' that "teachers would like to be imbedded in classroom observation" (p.31).

The present study seeks to address the existing yawning gap in the literature by providing a framework for depicting the necessary professional skills of supervisors. As such, it seems it is the first of its kind to tackle the issue, as far as the Iranian context and culture is concerned. Studies on the knowledge base of language teacher supervisors, to the best of the knowledge of the authors of the present investigation, are nonexistent and are yet to be embarked on. It is hoped that the studies such as the one embarked on by the present researchers will spark off similar investigations in the much undeservedly neglected field of language teacher supervision, in particular, in the context of Iran.

\section{Method and data}

The data for the present study comes from four focus group interviews (two conducted with four MOE supervisors in each group and two with four seasoned teachers in each group as informants), three one-on-one interviews with teachers, and fifteen mailed (returned) open-ended questionnaires (four completed by supervisors and eleven by teachers). The mailed questionnaires were more compact and focused compared to those conducted with groups of informants and, of necessity, they were of a structured type.

Sometimes conceived of as a specific category of interviews, focus groups have several informants respond to the researcher's questions and probes at the same time. The informants have the leeway to challenge each other's views if need arises. The rationale for conduction of focus groups as a major part of this study rather than one-on-one interviews is that the dynamics of focus groups allow for the investigator's access to more in-depth naturalistic data. In the words of Kleiber (2004)

The focus group operates on the assumption that the whole is greater than

the sum of its parts. In other words, the choice of focus groups is not justified

simply by being an efficient alternative to conducting, say, seven interviews in sequence. Rather, the method depends on the interaction of the group to stimulate participants to think beyond their own private thoughts and to articulate their opinions (p. 90).

Another justification for conducting focus groups was that, providing it is done well, it is bound to get around with the problem of social desirability, which is assumed to be a pitfall of doing interviews. It is the case when "respondents want to please the interviewer by giving socially acceptable responses that they would not necessarily give on an anonymous questionnaire" (Ary, Jacobs, \& Sorensen, 2010, p. 381)

The informants in this study were briefed on the procedures for conducting focus groups and a specific time and location was decided on. The second researcher designed a semi-structured interview schedule with six questions each accompanied by one or two probes. As stated previously two separate four-supervisor focus groups and two separate four-teacher ones were conducted with the second researcher being the moderator of the interview sessions. The questions posed were based on the second researcher's experiences as a former MOE supervisor and a careful perusal of the relevant literature. Two professors of Teaching English as a Foreign Language (TEFL) affiliated with Shiraz University (including the first researcher) helpfully concurred with a reading of the interview items and commenting on them. The end product was an interview schedule whose problematic areas were dwindled by the three individuals involved in reading or developing it. It followed more or less the same format for groups of teachers and supervisors alike. The same questions formed the basis of the open-ended questionnaire sent to 37 teachers and supervisors (the return rate as reported was 15). With prior consent and assurance of anonymity, the focus groups and one-on-one interviews were sound-recorded. Initially, the participants were asked whether they favored conduction of interviews in English or Farsi. Each interview lasted approximately more than one hour. They were then transcribed (the result being 47 A4 pages of interview data - see appendix 1 for a sample of the transcribed data) and the resulting texts were returned to the informants to be double-checked. They were subsequently subjected to qualitative data analysis.

Qualitative data analysis, being "typically inductive and data driven" (Duff, 2008, p.160), takes on different forms and is enshrouded in a plethora of terms. The essence of the mechanism, however, is the same. The researchers working within this paradigm or practice seek to make sense of the data gleaned naturalistically. The investigators are mostly set on spotting patterns or associations encoded in the data. The process described variously as iterative, cyclical, or inductive starts with the first bits of the data. With regards to the present data, analysis began immediately after conducting first interview. The tape was listened to again and again in search for prominent codes, categories, and themes.

Having come up with some themes, the researchers made an attempt at checking the validity of their findings in the form of themes and categories by seeking what has come to be known as 'member checks' (Ary, Jacobs, \& Sorensen, 2010 , p. 500). In this technique, "the researcher may ask participants to review and critique ... tape recordings for accuracy and meaning" (ibid). The researchers, having typed the interview recordings in a verbatim fashion in the Word Processor 2010 and coming up with themes, put their findings in the form of comments at the margin of the remarks of 
each informant and sent them to the same participants asking them whether they would concur with the codes identified or not. Wherever there were inconsistencies or points needing clarification, those pointed were subjected to negotiation. The final themes with regards to the issue of the knowledge base of MOE supervisors were the result of the demanding procedure recounted thus far.

\section{Findings}

\subsection{A Framework of Supervisory Skill/Knowledge Domains}

The present mini-study, being part of a large-scale mixed-methods investigation on the subject of foreign language supervision, yielded, among other things, the elements of a framework for the knowledge base of language teacher supervisors in the form of the following skill/knowledge domains:

\subsection{Public relations skills}

The ability to establish rapport and to deem yourself on a par with the teachers was a theme recurrently mentioned by the informants in the study as a main prerequisite for conducting supervisory responsibilities. This insistence on the 'people' skills of supervisors is not only indicative of the average teacher's downright discontent with the current supervisory conduct but also of a perceived trend towards more humanistic approaches to the supervisor's dealings with teachers. The following quotes, having their origin either in interview discussions or in responses to open-ended questionnaires, typify this attitude towards the issue at hand:

To me, everybody [English teachers] should be put in the picture with regards to their problematic areas. This should be done in an indirect and a non-reprimanding manner. Options should be proposed [by the supervisor]. (English translation of a teacher's quote)

If the purpose [of supervision] is to rectify the ills of the current educational system, teachers will be more receptive of ideas put to them on friendly terms rather than on an official note. (English translation of a supervisor's quote)

The bottom-line issue here is that unless the supervisor is tactful in their dealings with teachers and understanding enough of the real challenges they are presently facing, teachers will "feel demeaned by the paternalistic, distrustful dynamic at work in conventional evaluation" (Marshall, 2009, p. 32).

Along similar lines, mention is made of the need for a supervisor to be equipped with or, for that matter, trained in the relevant supervisory discourse. A few interviewees asserted that the manner through which something is conveyed by the supervisor takes precedence, at least, initially, over what is going to come across to them. Simply put, 'howness' comes first to them than the mere 'whatness' of the issue. For instance, supervisors should enshroud their remarks or suggestions in hedging expressions:

If the observer, involved in the act of observing a teacher's class, points to the said teacher's failings in some pedagogical issue in an appropriate way, there will be no defensiveness on the part of the teacher and they take the supervisor's advice but if simple problematic areas are brought home to the teacher [in a bossy manner], the teacher will turn a deaf ear to supervisorial comments and will be on the defensive. (English translation of a supervisor's quote)

This guarded attitude towards the way supervision is going to happen in educational settings is realized in our data, time and time again, in the technical word defensiveness. This is a sentiment which cuts the teacher off the supervisor and widens the allegedly widening gap in the relationship between Iranian English teachers and supervisors.

\subsection{Subject matter knowledge}

Still another type of knowledge required of an adept supervisor in the eyes of both seasoned teachers and supervisors is a supervisor's perfect familiarity with the content area being taught in the classes they are going to observe i.e., general proficiency in and sufficient knowledge of the components of the language. The informants interviewed maintained that teachers needed to turn to 'an authority' whenever they faced an educational problem:

To me, what comes first is [for a supervisor] to be equipped with perfect general English [knowledge] in terms of grammar, pronunciation, and the like so that they can make an impression [on teachers]. (English translation of a supervisor's quote)

I think some percent should be their [supervisors'] proficiency; otherwise teachers won't accept him [sig] and will not go to him [sig] ... . (a supervisor's remark originally in English)

Well, I remember I've always been a challenge to my colleagues [supervisors] back in ... our city regarding language proficiency. So when I was observed I could feel this in the observer's eyes ... their impression was based on the linguistic proficiency since they didn't see themselves as proficient as I was. (a supervisor's remark originally in English) 
Nearly all the informants, teachers and supervisors alike, maintained that having a sound and solid basis in general English proficiency is necessary but not sufficient. Hands-on experience of teaching those points taught to groups of learners with varying degrees of ability studying in ordinary as well as first-grade quality schools accounted for the rest of the said knowledge type. This assertion was almost always accompanied, in the remarks of the informants and interviewees, by an insistence on the fact that the supervisor should have gone through a sort of a hierarchy of teaching different grades and schools of different natures:

Sometimes we come across individuals who have much theoretical knowledge of English and have read a number of books but who haven't taught [some levels/books] in practice, unfortunately. Such people have quite unrealistic expectations of teachers. The teacher, who comes to know this [deficiency] won't take their advice. (English translation of a supervisor's quote)

In our gatherings we have seen guys [supervisors] who possess the necessary expertise but it's quite evident that he/she is lacking in an experiential basis in teaching. Such a guy talks 'from high'. (English translation of a teacher's quote)

\subsection{Pedagogical content knowledge}

Another domain of knowledge deemed vital in the eyes of teachers and supervisors (as far as the informants in the present mini-study are concerned) for the efficiency and effectiveness of MOE language supervisors is their familiarity with the pedagogical content knowledge. By pedagogical content knowledge, we understand what Shulman described as "the ways of representing and formulating the subject which make it comprehensible to others" (Shulman, 1986, as cited in Burns \& Richards, 2009). In other words, unlike the previous knowledge type i.e., subject matter which has to do with the content covered in language classes (in this particular regard, English language), pedagogical content knowledge, for the purposes of this study refers to the way English language is employed as a medium through which to get across things to learners. This knowledge domain includes theories of language learning and teaching, linguistic theories, and psychological theories, inter alia. The need for the MOE supervisor to have a good command of such knowledge is showcased throughout our data in the quotes of teachers and supervisors alike:

In regard to teaching methodologies, there may be some teachers who have difficulty understanding and implementing those methods or techniques ... the supervisor can aid them with illuminating such things. The observer can teach certain skills and methods. (English translation of a teacher's quote)

The second role the supervisor can take is the role of the resource ... the person [supervisor] who is updated enough to introduce new materials, new ways of teaching ... (a supervisor's remark originally in English)

\subsection{Contextual knowledge/cultural sensitivity}

The last skill type/knowledge domain brought up by the participants in the study is related to the need for an MOE supervisor to be cognizant of and familiar with the context of situation and context of culture. This significant issue was echoed and realized in the remarks of the informants in the form of several themes of concern to them either as teachers or as supervisors. The most recurrent of those themes are:

- gender issues: Female supervisors believed that they had much more problems in their supervisorial roles than male supervisors. Similarly, some male supervisors described the obstacles in the way of observing some girls' schools - the obstacles having to do with the specific cultural and religious values dominant in the Iranian society at large:

I think the gender of the supervisor is always also important because as a female supervisor I couldn't do my job very properly because I couldn't go to boys' class and I think in our male-dominated society a male supervisor is better to do the job. (a supervisor's remark originally in English)

- issues related to the educational system: The participants engaged in the interviews were nearly unanimously of the opinion that the current (secondary) educational system in Iran is to be partly or totally blamed for the inefficiency of some teachers and supervisors. They attributed the failings of the system in getting teachers to make progress to factors such as lack of a reward/penalty system, recruiting fully tenured teachers some of whom not caring about receiving a negative evaluation by the supervisor, allocation of an insufficient amount of time to supervision, making supervisors get caught in administrative bureaucracy, and so forth:

I think the first thing is that the person [the supervisor] should be familiar with the situation and the limitations...

\section{Conclusion}

The present study was an attempt at identifying the elements of knowledge base of supervisors working within the (secondary) educational system in the Iranian context. The investigation is predicated on the themes grounded in naturalistic data - data pooled mostly in the form of one-on-one and focus group interviews. The informants delineated the general knowledge types/skill domains deemed as necessary for a good functioning of observers. 
The limitations associated with (small-sample) qualitative studies notwithstanding, the present investigation is supposedly the first to scratch the knowledge base of the Iranian MOE supervisors. The study can be taken up with quantitative investigations in an attempt to come up with a comprehensive model of supervisory duties and skills.

The research can have implications for language teacher education in some respects. Firstly, (training) courses on supervisory skills can be subsumed into the overall teacher training programs in the country, especially now that the Iranian Ministry of Education has launched its own university i.e., Farhangian University. Secondly, in-service training courses can be held for the MOE language teacher supervisors with an eye to teaching such subjects as psychology (with an aim to further their 'people' skills), discourse analysis (with an aim to improve the way they address teachers in conferences), SLA and Applied Linguistics (with the purpose of building upon their pedagogical content knowledge), among other things.

In sum, it can be said that unless supervisors are well equipped to take over or take up their job, they cannot feed in the kind of "moral, technical and educational support" (Kayaoglu, 2001, 103) that teachers need. And this, in the long run, may mean damage to the whole make-up of a society set on hastening its progress in all areas.

\section{References}

Acheson, K. A., \& Gall, M. D. (2011). Clinical supervision and teacher development: Preservice and inservice applications $\left(6^{\text {th }}\right.$ ed.). New York: John Wiley \& Sons.

Akbari, R., Ghafar Samar, R., \& Tajik, L. (2006). Developing a classroom observation model based on Iranian EFL teachers' attitude. Journal of Faculty of Letters and Humanities, 198, 1-38.

Anderson, R. H. (1982). Creating a future for supervision. In In Thomas Sergiovanni (Ed.), Supervision of teaching (pp. 181-190). Alexander VA: ASCD.

Ary, D., Jacobs, C., \& Sorensen, C. (2010). Introduction to research in education. Belmont, CA: Wadsworth.

Bailey, K. M. (2006). Language teacher supervision: A case-based approach. Cambridge: Cambridge University Press.

Burns, A. \& Richards, J. C. (Eds.) (2009). The Cambridge guide to second language teacher education. New York: Cambridge University press.

Dahmardeh, M. (2006). A Preliminary research on textbook evaluation: How to make the Iranian secondary school's English language textbooks communicative? Unpublished master's thesis, University of Lancaster, Lancaster, Great Britain.

Dahmardeh, M. (2009). English language teaching in Iran and communicative language teaching. Unpublished PhD thesis. Warwick University, Great Britain.

Daresh, J. C. (2001). Supervision as proactive leadership ( $3^{\text {rd }}$ ed.). Prospects High, IL: Waveland Press.

Duff, P. A. (2008). Case study research in applied linguistics. New York, NY: Laurence Erlbaum Associates.

Gebhard, J. G. (1984). Models of supervision: Choices. TESOL QUARTERLY, 18(3), 501-514.

Goldsberry, L. (1988). Three functional methods of supervision. Action in Teacher Education, 10(1), 1-10.

Kayaoglu, M. N. (2012). Dictating or facilitating: The supervisory process for language teachers. Australian Journal of Teacher Education, 37(10), 103-117.

Kennedy, J. (1993). Meeting the needs of teacher trainees on teaching practice. ELT Journal, 47(2), 157-165.

Kiany, GR., Mahdavi, B., \& Ghafar Samar, R. (2011). Towards a harmonized foreign language education program in Iran: National policies and English achievement. Literacy Information and Computer Educational Journal (LICEJ), 2(3), 462-469.

Kleiber, P. B. (2004). Focus groups: More than a method of qualitative inquiry. In K. deMarrais \& S. D. Lapan (Eds.), Foundations for research: Methods if inquiry in education and the social science (pp. 87-102). Mahwah, NJ: Laurence Erlbaum Associates, Inc.

Marshall, K. (2009). Rethinking teacher supervision and evaluation: How to work smart, build collaboration, and close the achievement gap. San Francisco, CA: Jossey-Bass.

Pishghadam, R., \& Mirzaee, A. (2008). English language teaching in postmodern era. TELL,2(7), 89-109.

Stones, E. (1984). Supervision in teacher education: A counseling and pedagogical approach. London: Methuen \& CO LTD. 


\section{Appendix}

\section{Sample of interview data}

Interviewer: Which qualities do you think an MOE, specifically, an MOE lg teacher supervisor should possess or should be equipped with to ... so that he/she can do their job well?

H:Well, I remember I've always been a challenge to my colleagues back in ... our city regarding lg proficiency. So when I was observed I could feel this in the observer's eyes. They tried to establish this at the very beginning that this is sth perfunctory. I'm doing lip service so please do not take it to your height. Do not take it seriously. I'm not going to judge you. I'm not in a position to judge you. I'm aware of this and their impression was based on the linguistic proficiency. Since they didn't see themselves as proficient as I was. That was their idea. I'm not contending this. They thought that they should not observe me being lower at a lower level when it comes to $\mathrm{lg}$ proficiency. So they thought that the idea of a good teacher or an excellent teacher was that we need to be a proficient teacher to be an excellent teacher. While this is not the truth as TEFL warns us of this so I believe we need to establish er ... a comfortable a trusting atmosphere a rapport which you mentioned with the teacher. And the Ministry should take this business seriously by not asking me to observe a physics teacher. I'm a lg teacher. I'm not supposed to observe a history teacher. Because I've no idea of the way history should be taught. And There should be assurance fully tenured teachers feel that nothing is going to happen. And we've got an example here in Shiraz District One. There is a math teacher and on the first look or on the first impression you could easily tell that he is consuming drugs. And the only way to come up to live, let's say, peacefully within the system for the superiors and for the teachers to have him teach sporadically extracurricular hours to Shahed students and when it comes to teaching I've seen this myself. The students attend his class on the first occasion on the first day of the course. And then they get to know that this teacher has nothing to say their own school teacher is bbetter they keep being absent and the teacher keeps being present at the school. So he has done his job he has taught nothing. And ... another interesting thing is that the only thing he does is to sleep in the school manager's office (laughter) while the students are absent because no one attends his class (laughter). This is what the managers all know this is what the guys in the Office the Center office are aware of but since this guy has been teaching for twenty five years based on what he said a couple of weeks ago and a interesting thing he said 'being a supervisor er ... being a teacher for these students this year I realized that how easy the job of a school manager and a school superintendent is (laughter) sleeping in the office all the time. This is how we see supervision. We're being supervised and teachers of those courses are being supervised. Since he's not teaching his supervision is also excellent but while you are doing nothing I could not judge you as a malfunctioning practitioner. We're doing nothing we're just sitting there I cannot judge you by your appearance or your perfume of course this is an extreme case. There are cases like this. This guy should be expelled. To me there should be a plan to take care of their financial ... that this man needs help he shouldn't be a teacher. And there are other cases like I said why do we take non-governmental or non-state-run schools as our priority to be observed being a teacher at one of those schools last year the school manager warned me of being observed as the first school of the city it was the center of attention. (- non-profit schools) no not non-profit schools non-governmental school (- ...) because non-profit schools are for profit they make money. The students have to pay not public schools. Private schools, let's say. So there is a difference we don't see a school at a remote village as equal to a private school where the children of officials governmental officials study there and teachers try to be lenient. I see myself as a strict teacher and I try to stick to what I say I say the rubrics at the beginning although I'm flexible at the beginning but once the rules are set the criteria are set the rules and regulations I stick with them and I never go back on what I say. 